\title{
ÍNDICES DE RISCO DE FOGO DE HAINES E SETZER EM DIFERENTES CONDIÇÕES CLIMÁTICAS
}

\author{
index of risk of fire haines and setzer under differents climatics conditions
}

\author{
Anailton Sales de Melo* \\ Flavio Barbosa Justino** \\ Ewerton Cleudson Sousa Melo*** \\ Thiago Luiz do Vale Silva****
}

\begin{abstract}
Resumo
As queimadas, a nível global, são a segunda maior fonte de emissões de Gases de Efeito Estufa (GEE). Diante da necessidade de se conhecer possíveis implicações das mudanças na circulação atmosférica em um futuro próximo, pretende-se neste trabalho investigar a suscetibilidade do ambiente a ocorrência de queimadas, baseado nos índices de risco de queimadas, a saber: o Indice de Haines (IH) e o Índice de Stezer (IS). Para tanto, dados de modelagem numérica do modelo ECHAM5/MPI-OM, e dados das reanálises do NCEP são empregados para os cálculos dos (IH) e (IS) em dois períodos: atual (1980-2000) e projeções climáticas para o final do século (2080-2100). Com base nos resultados, concluiu-se que os modelos de risco de fogo reproduzem bem as áreas com maior incidência de queimadas sob condições atuais e que sob condições de aquecimento global detectou-se um aumento na área de risco em especial para a região Amazônica para o IS.
\end{abstract}

Palavras-chave: Risco de queimadas, Climatologia, Mudanças climáticas, Aquecimento global.

\begin{abstract}
Vegetation fires are the second source of greenhouse gas emissions into the atmosphere. An important step to reduce the climate impact of these emissions is the investigation of the atmospheric susceptibility of a region for fire development (fire risk). This study aims to investigate the environmental susceptibility to fire development, based on fire risk model: the Haines Index (IH) and the Stezer (IS) index. The study was carried out with data from the ECHAM5/MPI-OM climate model and the NCEP reanalysis data, to calculate both indices during two periods: present day (1980-2000) and climate projections for the end of the 21st century (2080-2100). Based upon the results, we concluded that the Haines index could reproduced property the areas with the highest fire incidence under present conditions. Moreover, it has been found that below under greenhouse warming conditions there is an enlargement in the fire risk area, in particular for the Amazon region to the IS
\end{abstract}

Key words: Risk of fire, Climatology, Climate Change, Global Warming.

\begin{abstract}
Resumen
Los incendios a nivel mundial, son la segunda fuente de emisiones de gases de efecto invernadero (GEI). Teniendo en cuenta la necesidad de conocer las posibles implicaciones de los cambios en la circulación atmosférica en el futuro cercano, tenemos la intención de este trabajo para investigar la susceptibilidad del medio ambiente al fuego sobre la base de las tasas de riesgo de incendios, a saber, el índice de Haines (IH ) y el Índice de Setzer (IS). Para ello, el modelo de datos ECHAM5/MPI-OM modelación numérica, y los datos del reanálisis del NCEP se utilizan en el cálculo de (IH) y (IS) en dos períodos: las proyecciones actuales (1980-2000) y el clima para el fin siglo (2080-2100). Basándose en los resultados, se concluye que los modelos de riesgo de incendios se reproducen bien las zonas con mayor incidencia de los incendios en las condiciones actuales y que, en condiciones de calentamiento global ha detectado un aumento en el área de riesgo, en particular, en la región amazónica a lo IS.
\end{abstract}

Plabrass claves: Riesgo de incendio, Clima, Cambio climático, Calentamiento global

(*) Doutorando em Meteorologia da Universidade Federal de Campina Grande - Rua Aprígio Veloso, 882, Bloco CL, Bodocongo, CEP: 58.429-140 - Campina Grande (PB), Brasil Tel./Fax: (+55 83) 21011323 / 33101202 - anailton@dca.ufcg.edu.br

${ }^{* * *}$ ) Prof. Dr. da Universidade Federal de Viçosa - Av. P.H. Rolfs, s/nº, Campus Universitário - CEP 36.570-000 - Viçosa (MG), Brasil . Tel./Fax: (+55 31) 38992729 / 38992735 - fjustino@ufv.br

(***) Pós-Doutorado em Geofísica na Universidade Federal do Rio Grande do Norte - Centro de Ciências Exatas e da Terra, Depto. de Geofísica, CEP 59078-970, Natal (RN), Brazil. - esmelo@yahoo.com

(****) Mestrando em Meteorologia da Universidade Federal de Campina Grande - Rua Aprígio Veloso, 882, Bloco CL, Bodocongo, CEP: 58.429-140 - Campina Grande (PB), Brasil Tel./Fax: (+ 55 83) 21011323 / 33101202 - thiago.luiz.lx@ gmail.com 


\section{INTRODUÇÃO}

Há tempos os povos têm percebido a estreita relação entre o homem e o clima, devido à influência das variações climáticas no bem-estar social. As atividades agropecuárias cresceram com a necessidades de atender o consumo associado ao aumento da população nos últimos 10.000 anos. As atividades agrícolas, por sua vez, necessitam de um manejo sazonal do solo, o que envolve na maior parte dos casos o uso do fogo. Analisando a história evolutiva do homem, de acordo com Laturner e Scherer (2004), este utiliza o fogo desde as mais remotas eras. Nas últimas décadas tem crescido a preocupação de vários setores da sociedade com o uso indiscriminado do fogo. $\mathrm{O}$ fogo cultural, associado às ignições de origem humana (Agee, 1993), no entanto, é tão ou mais importante que o fogo natural. Alguns dos mais importantes fatores que causam impactos sobre o clima e a biodiversidade são a queima de biomassa nos ecossistemas devido à expansão da fronteira agrícola, conversão de florestas e cerrados em pastagens, e renovação de cultivos agrícolas (KIRCHOFF, 1997; COSTA et al., 2007).

Queimadas e incêndios florestais nem sempre são atribuídos diretamente à ação humana. A ocorrência do fogo depende de alguns fatores que permitem o início da reação da combustão, em que a sua continuação depende principalmente da energia potencial armazenada no material combustível (RIBEIRO E SOARES, 1998). A exemplo, estudos palinológicos na região central do cerrado brasileiro indicam que a presença de carvão em reconstruções datando de 32.000 anos antes do presente (AP) (FERRAZ-VICENTINI, 1999; SALGADO-LABOURIAU; FERRAZ-VICENTINI, 1994). Este período esta compreendido na última era glacial (100.000 a 10.000 anos AP), caracterizado por um clima mais frio e seco em relação ao atual (JUSTINO, 2004; CRUZ et al, 2005). Todavia, muito pouco é sabido sobre as causas que levaram as condições suscetíveis ao fogo neste período. Acredita-se que a causa mais provável as queimadas glaciais foi à incidência de relâmpagos/raios.

Diante do exposto acima, este trabalho avalia a suscetibilidade da atmosférica para ocorrências de fogo baseados baseado nos índices de HAINES (IH) e de SETZER (IS). O IH tem sido amplamente utilizado na América do Norte e Austrália. Já o IS tem sido empregado no Brasil pelo CENTRO DE PESQUISAS ESPACIAIS E ESTUDOS CLIMÁTICOS (CPTEC), no grupo de pesquisa de queimadas.

\section{DADOS UTILIZADOS}

\section{Reanálises do NCEPINCAR}

Neste estudo, as análises foram realizadas utilizando uma climatologia de 20 anos para o período de jan/1980 a dez/2000. A confiabilidade das reanálises do NCEP/NCAR para o Hemisfério Sul (HS) melhora significativamente a partir de 1979, beneficiando-se da assimilação de dados de satélite, que completamentam parcialmente a escassez de observações convencionais Hines et al. (2000).

\section{Descrição do Modelo ECHAM5/MPI-OM}

As questões propostas foram investigadas relacionando as simulações numéricas do período atual com o cenário de Aquecimento Global (AG). Para tal fim foi utilizada a sexta geração do modelo acoplado ECHAM5/MPI-OM, desenvolvido no Instituto Max-Planck de Meteorologia (MPIM) de Hamburgo na Alemanha. Os dois componentes do modelo acoplados, a saber: o ECHAM5 para a atmosfera, e o MPI-OM para o oceano estão bem documentados (JUNGCLAUS et al., 2006). Nesse contexto, menciona-se que a configuração usada nesse estudo tem truncamento triangular no número de onda T63, aproximadamente $1,8^{\circ}$ de latitude e de longitude, o que representa uma 
resolução espacial de aproximadamente 180 x $180 \mathrm{Km}$, na faixa equatorial, com 31 níveis verticais. O modelo oceânico do Instituto Max Planck (MPI-OM) (MARSLAND et al., 2003) emprega as equações primitivas para um fluído hidrostático com uma superfície livre. A discretização possui 40 níveis verticais com uma resolução horizontal de $1,5^{\circ}$.

O cenário econômico proposto baseia-se no cenário A1B. Esse cenário climático projeta uma descrição de um estado futuro de emissões dos principais gases estufa e aerossóis. Para o cenário intermediário A1B, a concentração atmosférica de CO2 apresenta 775 ppmv (partes por milhão em volume) para o final do século XXI.

\section{Comportamento Climático}

Para um diagnóstico de quais variáveis climáticas são determinantes e quais regiões são mais vulneráveis às queimadas, é fundamental a análise do ciclo sazonal de temperatura (Temp), precipitação (Prec) e umidade relativa (UR), a partir de dados observados e/ou dados provenientes de simulações numéricas.

A investigação climática proveniente de simulação numérica necessita de uma avaliação de como estes resultados numéricos reproduzem os dados observados. Com este objetivo, a Figura (1a,b,c,d,e,f) mostram a distribuição espacial de temperatura do ar, precipitação e umidade relativa, provenientes de reanálises do NCEP e dos dados do modelo ECHAM5/MPI-OM, no período de junho a outubro entre os anos de 1980 a 2000. É durante os meses de junho a outubro que se detecta o maior número de queimadas no Brasil, todavia serão mostrados apenas os meses de Agosto e Setembro em que os resultados são mais evidentes.

Os dados do ECHAM5, todavia, diferem dos dados de NCEP, pois o modelo apresenta temperaturas mais altas em até $5^{\circ} \mathrm{C}$ em relação aos dados do NCEP. Comparando-se as Figuras (1a e 1b) observa-se que o ECHAM5 mostra ainda uma área com altos valores de temperaturas entre o Pará e o Amazonas, não existente nas reanálises. A distribuição espacial do campo de precipitação a partir dos dados do NCEP é apresentada na Figura (2c,d). Observa-se que com exceção da região sul e o noroeste da região norte, as precipitações são da ordem de (4 mm/dia) para ambos os dados (reanálise e modelo). Na região que se estende desde o oeste do Amazonas até a região sudeste, observa-se que os dados do ECHAM5, apresentam maiores valores de precipitação em comparação as reanálises devido a uma melhor reprodução da Zona de Convergência do Atlântico Sul (ZCAS). Embora esta tenha sua atividade enfraquecida nesta época do ano, que compreende os meses de junho a outubro. Nota-se ainda que ambos os dados apresentam padrões espaciais coerentes para o nordeste brasileiro (NEB), região sul e noroeste do Brasil.

Análise similar para a umidade relativa mostra que de acordo com as reanálises do NCEP, as regiões com menores valores de umidade relativa são o centro-sul do Mato Grosso e a faixa oeste do Mato Grosso do Sul (Fig. 1e). Em contrapartida, os resultados do ECHAM5 mostram os menores valores de umidade relativa deslocado para o centro-norte do Mato Grosso, centro-sul do estado do Pará e parte do Tocantins (Fig. 1f). 

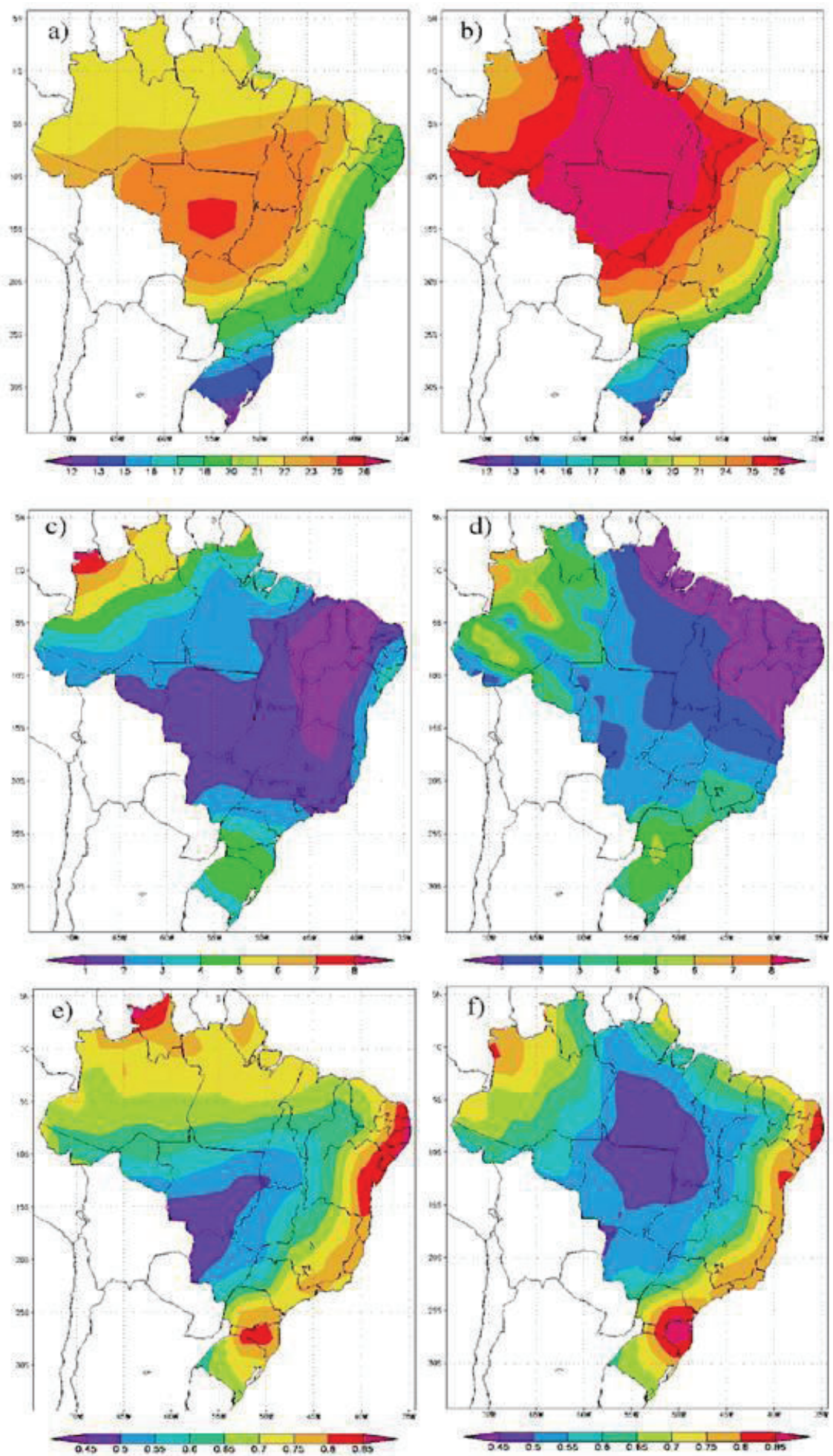

Figura 1 - Climatologia no período de junho a outubro, média dos anos 1980 a 2000.

Reanálises (NCEP): a) Temperatura $\left({ }^{\circ} \mathrm{C}\right)$, c), Precipitação $(\mathrm{mm} / \mathrm{dia})$, e) UR $(\%)$.

Simulações (ECHAM5): b) Temperatura $\left({ }^{\circ} \mathrm{C}\right)$, d) Precipitação $\left.(\mathrm{mm} / \mathrm{dia}), \mathrm{f}\right) \mathrm{UR}(\%)$

A segunda comparação entre os dados simulados e os dados provenientes do NCEP é feita via análise harmônica. A análise harmônica tem sido uma ferramenta útil no estudo dos padrões de elementos meteorológicos, representando as variações de uma série temporal como base de funções periódicas de senos e cossenos (ASLAN e TOPÇU, 1994). Estas funções apresentam frequências como múltiplos de uma frequência fundamental. Segundo WILKS (1995), uma dada série temporal de dados de amostras equidistantes de uma variável, pode ser representada por uma função harmônica: 


$$
y_{t}=\bar{y}+\sum_{j=1}^{N} C_{j} \cos \left(\grave{u}_{j} t-\ddot{o}_{j}\right)
$$

em que: $\quad \bar{y}=$ média dos valores da série, $N=$ número de observações, $C_{j}=$ amplitude; $\omega_{\mathrm{j}}=$ freqüência e $\phi_{\mathrm{j}}=$ ângulo de fase.

É possível escrever a equação anterior utilizando a função seno. No entanto, a função cosseno é geralmente utilizada, pois o ângulo de fase $(\phi)$ pode ser facilmente determinado como correspondendo ao tempo onde a função harmônica é maximizada:

$$
\mathrm{t}=\frac{\phi_{\mathrm{j}} \mathrm{N}}{2 \circlearrowright}
$$

As equações para os cálculos da amplitude dos harmônicos segundo EMERY e THOMSON (1997) são:

- Amplitude $\left(\mathrm{C}_{\mathrm{j}}\right): \mathrm{C}_{\mathrm{j}}=\sqrt{\mathrm{A}_{\mathrm{j}}^{2}+\mathrm{B}_{\mathrm{j}}^{2}}$

Temos: $A_{j}=$ coeficiente do cosseno; $B_{j}=$ coeficiente do seno e $C_{j}=$ vetor amplitude.

Os termos $A_{j}$ e $B_{j}$ são obtidos pelas seguintes fórmulas:

$$
A_{j}=\frac{2}{N} \sum_{t=1}^{N} y_{t} \cos \left(\frac{2 ð t}{N}\right) \quad B_{j}=\frac{2}{N} \sum_{t=1}^{N} y_{t} \operatorname{sen}\left(\frac{2 ð t}{N}\right)
$$

- Fase $(\phi)$

O ângulo de fase $\left({ }^{\phi}\right)$ é calculado a partir de uma das equações seguintes, dependendo do valor obtido para $\left(\mathrm{A}_{\mathrm{j}}\right)$ :

$$
\phi_{\mathrm{j}}= \begin{cases}\tan ^{-1} \frac{\mathrm{B}_{\mathrm{j}}}{\mathrm{A}_{\mathrm{j}}} & \mathrm{A}_{\mathrm{j}}>0 \\ \tan ^{-1} \frac{\mathrm{B}_{\mathrm{j}}}{\mathrm{A}_{\mathrm{j}}} \pm \text { ou } \pm 180^{\circ} & \mathrm{A}_{\mathrm{j}}<0 \\ \frac{\partial}{2} \text { ou } \theta^{\circ} & \mathrm{A}_{\mathrm{j}}=0\end{cases}
$$

O comportamento harmônico da temperatura observada e modelada é mostrado na Figura $(2 \mathrm{a}, \mathrm{b})$ para a precipitação na Figura $(2 \mathrm{c}, \mathrm{d})$ e para a umidade relativa na Figura $(2 \mathrm{e}, \mathrm{f})$.

As amplitudes de temperatura mostrada na Figura $(2 \mathrm{a}, \mathrm{b})$ ilustram que em geral existem pequenas variações zonais. Em ambos os conjuntos de dados a parte sul do Brasil apresenta as maiores variações sazonais de temperatura, devido a uma melhor definição das estações do ano. De acordo com os resultados propostos pelo modelo ECHAM5 existe uma região com substancial variação sazonal de temperatura, localizada sobre a parte norte do Mato Grosso e grande parte do Pará, com diferenças de temperatura nesta área podendo chegar a $4^{\circ} \mathrm{C}$. 

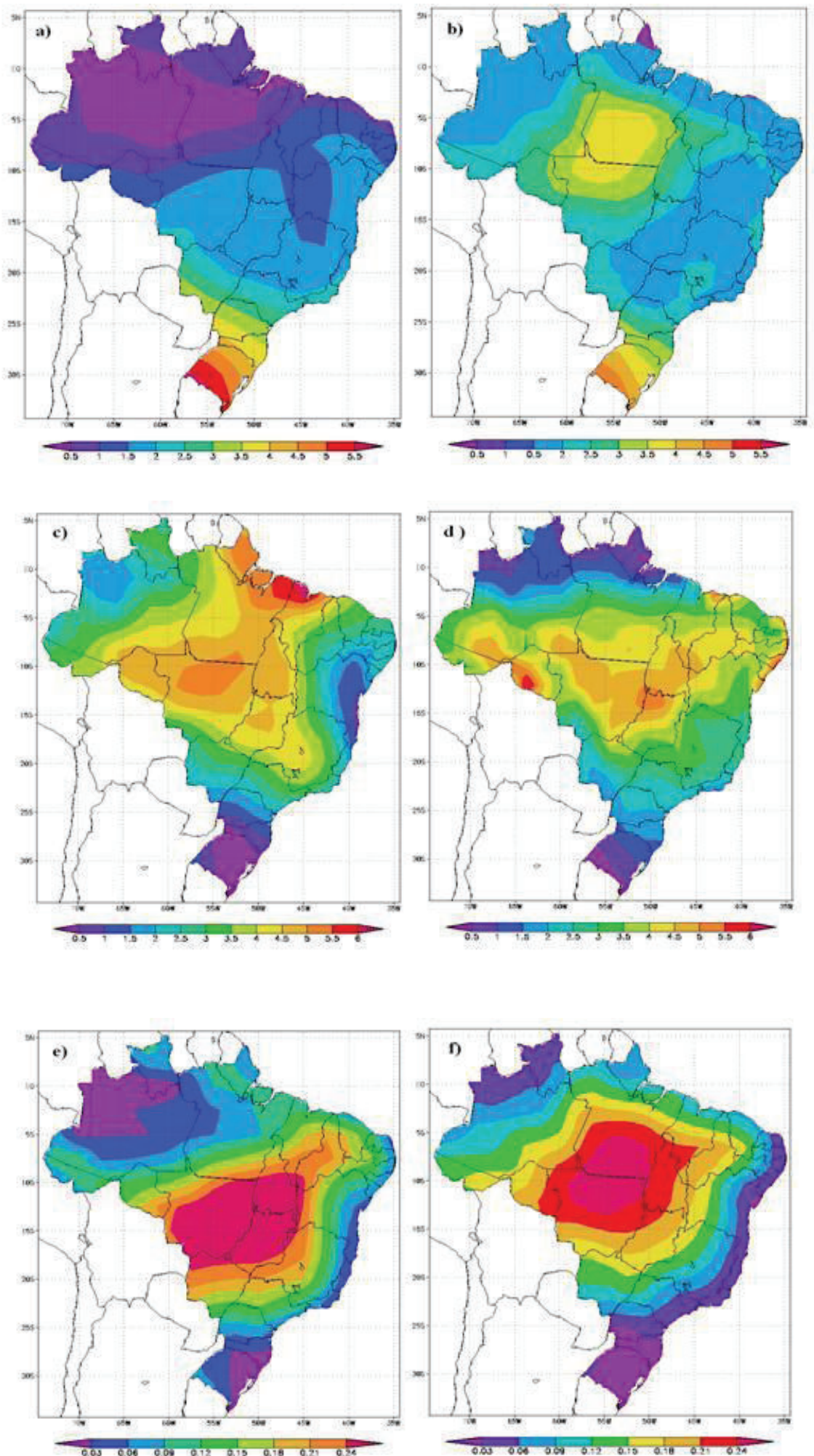

Figura 2 - Primeiro harmônico de junho a outubro, média dos anos 1980 a 2000 Reanálises da Amplitude (NCEP): a) Temperatura, c) Precipitação), e) UR (\%). Simulações da Amplitude (ECHAM5): b) Temperatura, d) Precipitação, f) UR.

As áreas de maiores taxas de precipitação tem uma grande distinção entre as estações chuvosa e seca. Na Figura (3c) destacam-se os estados do Acre, Amapá, Pará, Mato Grosso, Goiás, Tocantins, Bahia e Maranhão, com amplitudes entre 4mm-6mm. A Figura (2d), segundo os resultados do ECHAM5, apresenta as maiores taxas desde o sul da região norte, até o nordeste, e nos estados de Mato Grosso, Goiás, e Tocantins, com valores entre $4 \mathrm{~mm} /$ dia a $6 \mathrm{~mm} /$ dia. 
É importante notar que de acordo com os dados de ECHAM5, o estado do Pará tem as maiores variações sazonais da umidade relativa (Fig. 2f), característica não notada nos dados do NCEP (Fig. 2e). Maiores valores na amplitude da umidade mostram uma alta flutuabilidade entre os períodos quentes e secos, e os períodos frios e úmidos. Como será discutido adiante, estas áreas podem se caracterizar como zonas propícias as queimadas.

\section{MODELOS DE RISCOS DE QUEIMADAS}

\section{Índice de Haines ( Ih )}

As análises são feitas a partir do índice de baixa severidade atmosférica, o Índice de Haines (IH) tem como base a climatologia mensal do período atual (1980-2000) e o clima futuro (baseado no cenário A1B proposto pelo Painel Intergovernamental para as Mudanças Climática - IPCC entre 2080-2100). O IH apresenta uma forte relação com as condições de estabilidade atmosférica, ar seco, baixa umidade e o crescimento do fogo. Haines (1988) concluiu ainda que as temperaturas do ar (T) e do ponto de orvalho (Td) em diferentes camadas da atmosfera, juntamente com o baixo nível de umidade relativa (UR) na superfície, e o material combustível, influenciam significativamente no desenvolvimento de incêndios em grandes áreas. O Índice de Haines depende diretamente do nível da camada atmosférica. A combinação de três camadas na atmosfera (Baixa, Média e Alta) é usada para a elaboração deste índice, que é o somatório dos termos de estabilidade atmosférica com os termos de umidade do ar.

Matematicamente, o cálculo do Índice de Haines (IH) é definido pela soma do componente da estabilidade (A), e do componente da umidade atmosférica (B), como apresentado na tabela 1. Assim, $\mathrm{IH}=\mathrm{A}+\mathrm{B}$ : em que, o termo A representa a diferença de temperatura do ar entre dois níveis da atmosfera e o termo B caracteriza as diferenças entre as temperaturas do ar e as temperaturas do ponto de orvalho para cada nível da atmosfera, ou seja, a depressão do ponto de orvalho.

Tabela 1 - Ilustração das diferentes componentes do Índice de Haines (IH)

\begin{tabular}{|c|c|c|c|c|}
\hline \multirow{2}{*}{ Altitude } & \multicolumn{2}{|c|}{ Componente da Estabilidade (A) } & \multicolumn{2}{|c|}{ Componente da Umidade (B) } \\
\hline & Cálculo & Categoria & Cálculo & Categoria \\
\hline $\begin{array}{c}\text { Baixa } \\
(\leq 1500 \mathrm{~m})\end{array}$ & $\begin{array}{c}\mathrm{A}=\mathrm{T} 950 \mathrm{hPa}- \\
\mathrm{T} 850 \mathrm{hPa}\end{array}$ & $\begin{array}{l}A=1 \text { se }<4{ }^{\circ} \mathrm{C} \\
A=2 \text { se } 4-7^{\circ} \mathrm{C} \\
A=3 \text { se } \geq 8{ }^{\circ} \mathrm{C}\end{array}$ & $\begin{array}{c}\mathrm{B}=\mathrm{T} 850 \mathrm{hPa}- \\
\mathrm{Td} 850 \mathrm{hPa}\end{array}$ & 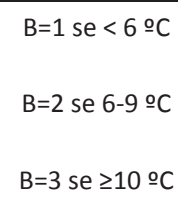 \\
\hline $\begin{array}{c}\text { Média } \\
\text { (1500-3500m) }\end{array}$ & $\begin{array}{c}\mathrm{A}=\mathrm{T} 850 \mathrm{hPa}- \\
\mathrm{T700hPa}\end{array}$ & $\begin{array}{l}A=1 \text { se } \angle 6 \circ C \\
A=2 \text { se } 6-10^{\circ} C \\
A=3 \text { se } \geq 11^{\circ} \mathrm{C}\end{array}$ & $\begin{array}{c}\mathrm{B}=\mathrm{T} 850 \mathrm{hPa}- \\
\mathrm{Td} 850 \mathrm{hPa}\end{array}$ & $\begin{array}{l}B=1 \text { se }<6 \stackrel{\circ}{ }= \\
B=2 \text { se } 6-12^{\circ} \mathrm{C} \\
B=3 \text { se } \geq 13^{\circ} \mathrm{C}\end{array}$ \\
\hline $\begin{array}{c}\text { Alta } \\
(\geq 3500 \mathrm{~m})\end{array}$ & 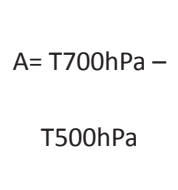 & $\begin{array}{l}A=1 \text { se } \angle 18^{\circ} \mathrm{C} \\
A=2 \text { se } 18-21^{\circ} \mathrm{C} C \\
A=3 \text { se } \geq 22^{\circ} \mathrm{C}\end{array}$ & $\begin{array}{c}\mathrm{B}=\mathrm{T} 700 \mathrm{hPa}- \\
\mathrm{Td} 700 \mathrm{hPa}\end{array}$ & $\begin{array}{l}B=1 \text { se }<15^{\circ} C \\
B=2 \text { se } 15-20 \circ C \\
B=3 \text { se } \geq 21 \stackrel{\circ}{ }=0\end{array}$ \\
\hline
\end{tabular}

Fonte: Winkler et al. (2005)

Nas análises optou-se em apresentar o risco de fogo (IH) em função da temperatura, a saber: índice muito baixo, com valores menores que $12^{\circ} \mathrm{C}$; índice baixo com valores compreendidos entre $13^{\circ} \mathrm{C}$ e $22^{\circ} \mathrm{C}$; índice moderado entre $23^{\circ} \mathrm{C}$ e $24^{\circ} \mathrm{C}$ e índice alto acima de $24^{\circ} \mathrm{C}$, conforme Tabela 2. 
MELO, A. S.; JUSTINO, F.; MELO, E. C. S.; SILVA, T. L. do V.

Tabela 2 - Cálculo do IH em função da temperatura

\begin{tabular}{c|c}
\hline Risco & $\mathrm{IH}$ \\
\hline muito baixo & $\leq 12^{\circ} \mathrm{C}$ \\
\hline baixo & $13{ }^{\circ} \mathrm{C}-22^{\circ} \mathrm{C}$ \\
\hline moderado & $23{ }^{\circ} \mathrm{C}-24 \circ \mathrm{C}$ \\
\hline alto & $\geq 24 \circ \mathrm{C}$ \\
\hline
\end{tabular}

\section{Índice de Setzer ( Is )}

Esta metodologia de Risco de Fogo (RF) foi desenvolvida internamente no CPTEC, com base na análise da ocorrência de centenas de milhares de queimadas nos principais biomas (tipos de vegetação) do Brasil, em função das condições e históricos meteorológicos na área de cada evento (SETZER et al., 2002; SISMANOGLU et al., 2002). Seu princípio é que quanto mais dias sem chuva, maior o risco de queimada da vegetação; adicionalmente, são incluídos no cálculo o tipo e o ciclo natural de desfolhamento da vegetação, temperatura máxima e umidade relativa mínima do ar, assim como a presença de fogo na região de interesse. A referência dos cálculos está nos "Dias de Seca" ou "Secura" (S), que é um número hipotético de dias sem nenhuma precipitação durante os últimos 120 dias (SETZER e SISMANOGLU, 2006).

\section{Sequência do Cálculo do Risco de Fogo Observado}

A seguir apresenta-se os passos para a obtenção do risco de fogo, proposto por Setzer et al. (2002) e definido no trabalho como Índice de Setzer (IS).

1) Determina-se diariamente para a área geográfica de abrangência, o valor da precipitação, em milímetros $(\mathrm{mm})$, acumulada para onze períodos imediatamente anteriores, de $1 ; 2 ; 3 ; 4$; $5 ; 6$ a $10 ; 11$ a $15 ; 16$ a 30; 31 a $60 ; 61$ a 90 e 91 a 120 dias.

2) Calcula os "Fatores de Precipitação" (FP), com valores de 0 a 1, para cada um dos onze períodos, por meio de uma função exponencial empírica da precipitação em milímetros de chuva para cada um deles. As equações são respectivamente:

$$
\begin{aligned}
& \mathbf{P}_{1}=\exp (-0,14 \mathrm{prec}) \mathbf{P}_{2}=\exp \left(-0,07 \mathrm{prec} \quad \mathbf{P}_{3}=\exp (-0,04 \mathrm{prec}) \quad \mathbf{P}_{4}=\exp (-0,03 \mathrm{prec}) \mathbf{P}_{5}=\exp (-0,02 \mathrm{prec})\right. \\
& \mathbf{P}_{6 \mathrm{a} 0}=\exp (-0,01 \mathrm{prec}) \mathbf{P}_{1 \mathrm{a}} \mathbf{5}=\exp (-0,008 \mathrm{prec}) \mathbf{P}_{\mathbf{6}} \mathrm{a} \boldsymbol{\theta}=\exp (-0,004 \mathrm{prec}) \\
& \mathbf{P}_{3} \text { a } \theta=\exp (-0,002 \mathrm{prec}) \mathbf{P}_{\boldsymbol{6}} \text { a } \theta=\exp (-0,001 \mathrm{prec}) \mathrm{P}_{\boldsymbol{O}_{\text {a } 120}}=\exp (-0,0007 \mathrm{prec})
\end{aligned}
$$

3) Calcula os "Dias de Secura" (PSE), pela multiplicação dos FP conforme a equação:

$$
\text { B } \left._{n=1,5}=0,9\left[1+\operatorname{sen} A_{n=1,5} \cdot P S E\right)\right] / 2
$$

4) Determina o risco de fogo básico (RB) para cada um dos cinco tipos de vegetação considerada, por meio da equação:

$$
\text { B } \left._{n=1,5}=0,9\left[1+\operatorname{sen} A_{n=1,5} \cdot P S E\right)\right] / 2
$$


Tabela 3 - Classe de vegetação usado no IS.

\begin{tabular}{c|c|c|c|c|c}
\hline CLASSE De Vegetação & $\mathbf{1}$ & $\mathbf{2}$ & $\mathbf{3}$ & $\mathbf{4}$ & $\mathbf{5}$ \\
\hline TIPO DE VeGETAÇÃo & Ombrófila & Ombrófila Aberta & Contato + Campinarama & Decídua+ & Não Floresta \\
& Densa & & & Semi-Decidua & \\
\hline CONSTANTE “A" & 1,715 & 2 & 2,4 & 3 & 4,7 \\
\hline
\end{tabular}

Fonte: Setzer et al., 2002

O Risco Básico (RB) segue uma curva senoidal ao longo do tempo, já que a radiação solar global e a resposta da vegetação apresentam aproximadamente este mesmo padrão. Desta forma, o risco aumenta segundo esta curva, atingindo o valor máximo de $(0,9)$. A Figura (3) ilustra a variação do risco básico utilizando as equações e conceitos anteriores. Nota-se que o eixo dos "dias sem chuva" indica tanto um período real de dias sem chuva, como também os "dias de secura", que correspondem a um período hipotético sem chuva calculado a partir da quantidade e distribuição temporal das chuvas ocorridas. A noção de períodos não chuvosos "dias sem chuvas" ou "dias de secura" se constitui no princípio básico deste método.

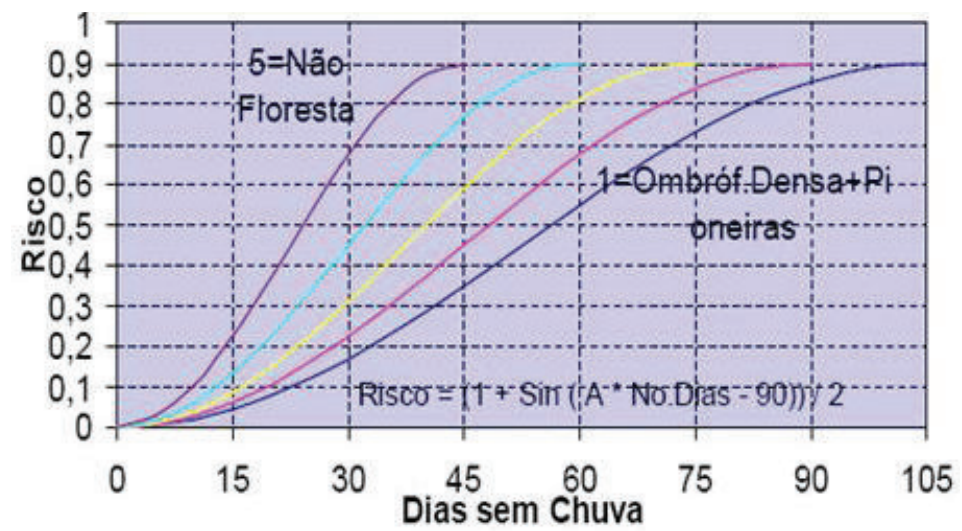

Figura 3 - Variação do risco de fogo (RF) para diferentes vegetações Fonte: Centro de Previsão de Tempo e Estudos Climáticos (CPTEC)

Somando-se ao fator de secura existem outros dois fatores para o risco de fogo final.

1) A correção do risco de fogo para a umidade relativa mínima do ar, pois o risco (RU) aumenta para umidade abaixo de $40 \%$ e diminui para valores acima desta referência. Usam-se os dados de umidade das observações das 18UTC, supostamente seu mínimo. A equação de ajuste linear é

$$
\mathrm{RU}=\mathrm{RB}\left(-0,006 \cdot \mathrm{UR}_{\operatorname{mín}}+1,3\right)
$$

2) Corrição do risco de fogo a temperatura máxima do ar. O risco (RT) aumenta para temperaturas acima de $30^{\circ} \mathrm{C}$ e diminui para valores abaixo desta referência. Usam-se os dados de umidade das observações das $18 \mathrm{~h}$ UTC, supostamente seu máximo. A equação de ajuste linear é:

$$
\begin{array}{r}
\mathrm{RT}=\mathrm{RU}\left(0,02 \mathrm{~T}_{\text {máx }}+0,4\right) \\
\text { Risco d Fogo Final }(\mathrm{RF})=\mathrm{RT}
\end{array}
$$


Feitos os cálculos tem-se que o risco em função da temperatura máxima é o risco de fogo final (RF), atribuindo-se as seguintes categorias:

Tabela 4 - Classes de risco de fogo

\begin{tabular}{c|c}
\hline Nível de RISCO & (IS) ÍNDICE De SETZeR ( 0 a 1) \\
\hline mínimo & $0-0.15$ \\
\hline baixo & $0.15-0.4$ \\
\hline médio & $0.40-0.7$ \\
\hline Alto & $0.70-0.90$ \\
\hline crítico & $>0.90$ \\
\hline Nível de Risco & (IS) ( 0 a 1) \\
\hline
\end{tabular}

Devido à dificuldade em mostrar o índice de Setzer (IS) na base diária, optou-se por sua apresentação a partir da climatologia mensal com dados diários.

\section{MUDANÇA NA VEGETAÇÃO}

Uma avaliação das consequências climáticas decorrentes de modificações de vegetação natural inclui, dentre outros fatores, o entendimento das condições atmosféricas e de superfícies. Por exemplo, o impacto em relação ao risco de fogo na floresta Amazônica ocorrendo a "savanização" da Amazônia.

Estudos recentes como os de Cook e Vizy (2008), baseados num modelo regional de clima acoplado a um modelo de vegetação potencial, propõem para o final do século XXI uma redução de cerca de $70 \%$ da floresta amazônica (ombrófila densa) para cerrado (semi-decídua). Esta distribuição atual e futura da floresta amazônica e outros biomas (Cook e Vizy, 2008) são mostradas na Figura (5.1a,b). Como o ÍNDICE DE SETZER (IS) utiliza a vegetação como função de entrada, calcula-se este índice assumindo-se estes dois cenários de vegetação.

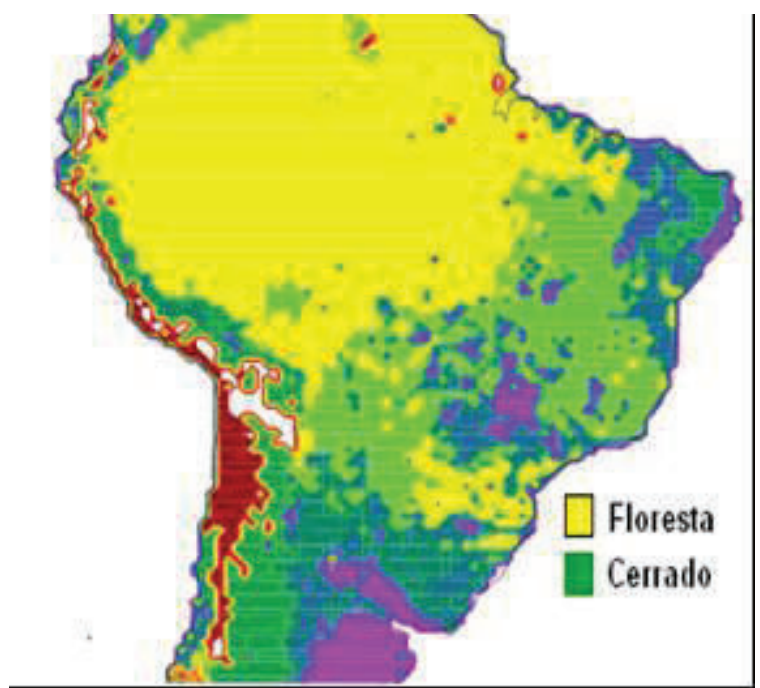

a)

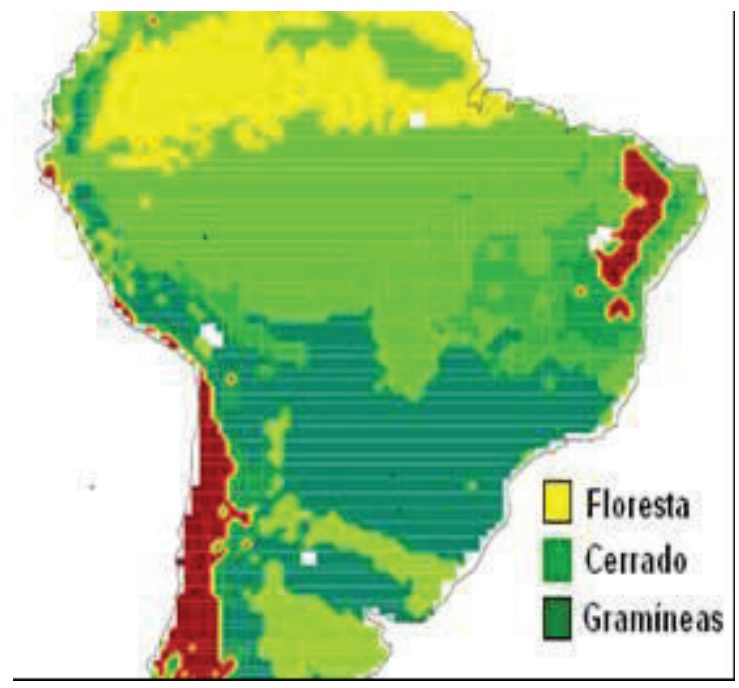

b)

Figura 4 - a) Distribuição da vegetação atual na América do Sul (AS);

b) Distribuição da vegetação prevista para o futuro na AS. Fonte: COOK E VIZY (2008).

Três avaliações são feitas: a primeira investiga o risco de fogo tendo como base o clima e vegetação atual (Fig. 4.1a). A segunda análise parte do clima futuro (2080-2100) e não se considera 
as mudanças na vegetação, utilizando a distribuição de biomas como o atual. O terceiro cálculo é feito considerando o clima e vegetação como para o cenário futuro, em que a vegetação de floresta (ombrófila densa) muda para cerrado (semi-decídua), e áreas de cerrados se transformarão em gramíneas (não floresta) conforme Figura (4.1b).

\section{RESULTADOS E DISCUSSÕES}

No que segue são apresentados os comportamentos dos termos A, B e IH para os dados do NCEP e ECHAM5 para condições climáticas diferentes; e os fatores de risco que constituem o IS, tais como: o fator de temperatura máxima (Tmáx), o fator de umidade (URmín) e o índice de secura (PSE) para os meses de agosto e setembro. Deve-se notar que a maior parte das queimadas no Brasil é de origem antrópica, mesmo que o risco de queimadas seja máximo, isto não implica na presença do fogo. O caso é diferente da América do Norte (AN), onde boa parte das queimadas é de origem natural. Estes índices (IH e IS) fornecem unicamente a suscetibilidade da atmosférica à ocorrência de incêndios florestais.

\section{Análise para o Índice de Haines (IH)}

Análise para o mês de agosto

Observou-se na média atmosfera para o mês de agosto que o componente da estabilidade (termo A) para os dados do NCEP (Fig. 5a), apresenta categoria 2 para as regiões sul, nordeste e norte da região norte. $\mathrm{O}$ sudeste do Amazonas, sul do Pará e a região centro-oeste apresenta categoria 3. O componente da umidade (termo B) (Fig. 5b) apresenta categoria 1 na parte norte da região norte e na região nordeste; categoria 2 para as regiões sul, sudeste e centro-oeste, e valores moderados (3) para o centro-sul do Mato Grosso. Com isso, o IH (Fig. 5c) é caracterizado por alto risco para a região centro-oeste com temperaturas acima de $\left(24^{\circ} \mathrm{C}\right)$, e risco moderado (5) para as demais regiões.

Os resultados do ECHAM5, quando comparado aos resultados do NCEP, apresentam uma área de maior abrangência do termo (A) com diferente distribuição espacial de categoria (3), o que sugere uma maior instabilidade atmosférica (Fig. 5d). Para o termo (B), nota-se que o modelo apresenta um clima mais úmido que o proposto pelo NCEP, já que a diferença entre a temperatura do ar e a temperatura do ponto de orvalho é menor para o ECHAM5 (Fig. 5e). Esta umidade não é suficiente, todavia, para reduzir o risco de queimada na área que se estende desde o Mato Grosso até o Pará (Fig. 5f). 


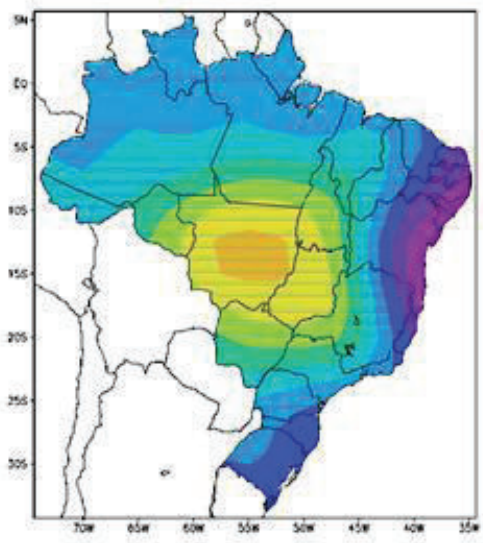

a)

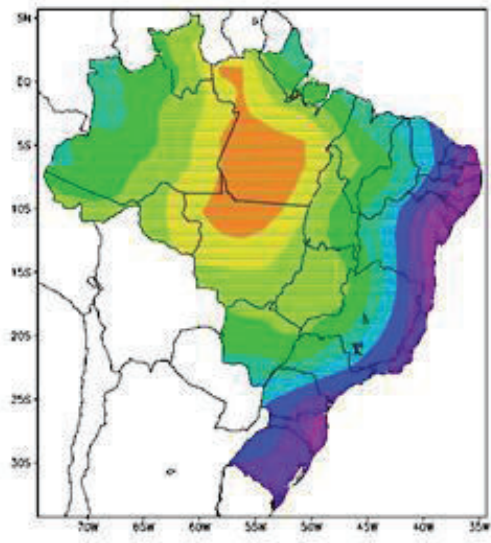

d)

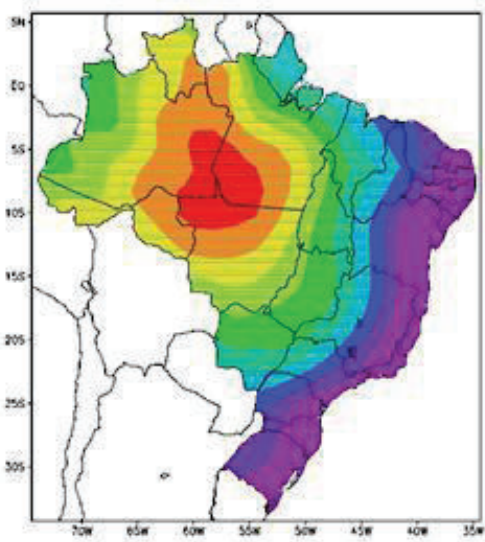

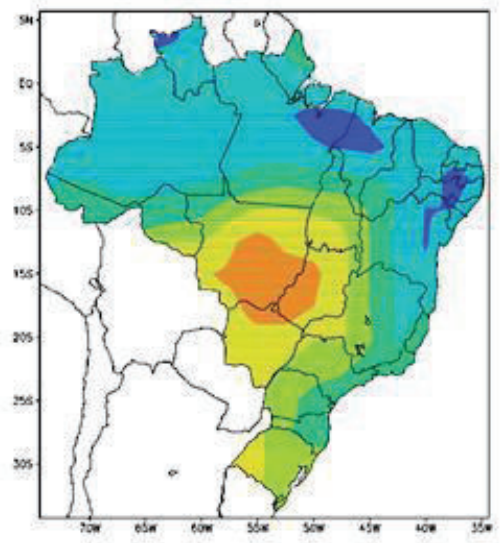

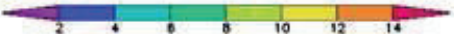

b)
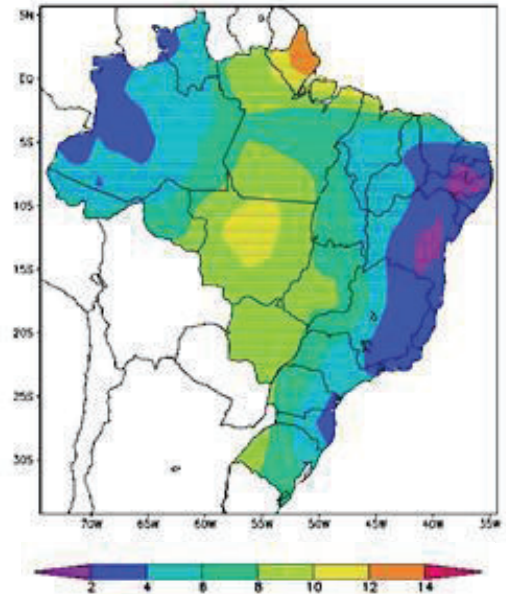

e)

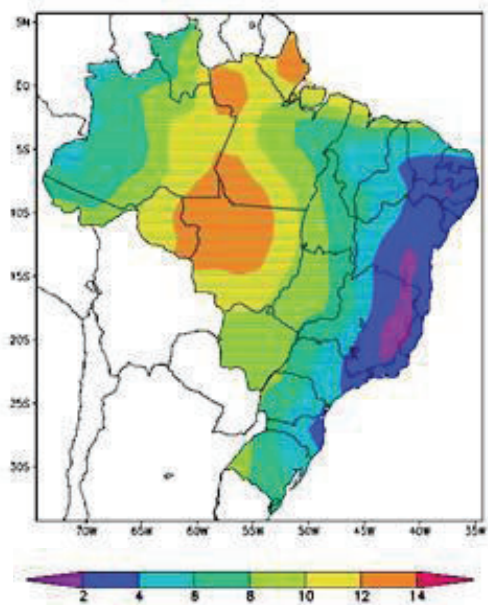

h)

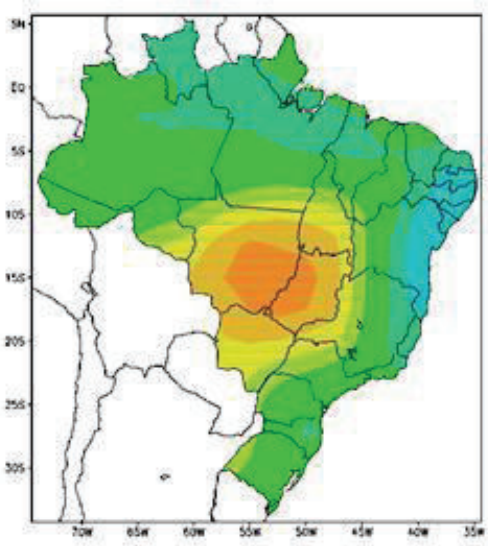

c)
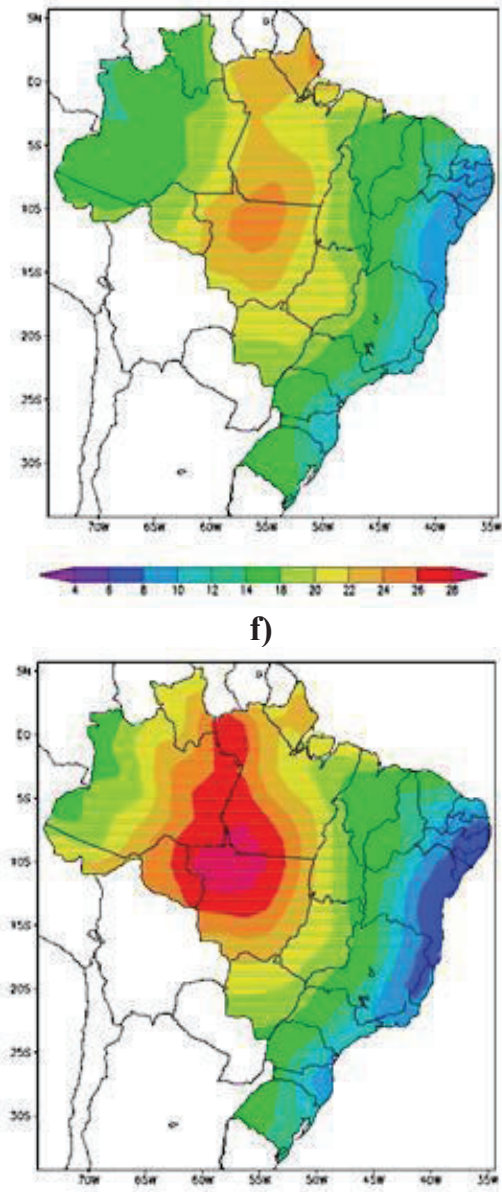

Figura 5 - Suscetibilidade do ambiente a ocorrências de queimadas sob condições atuais do presente a partir dos dados do NCEP para o mês de agosto: a) Termo A, b) Termo B, c) Índice de Haines. Suscetibilidade do ambiente a ocorrências de queimadas sob condições atuais a partir dos dados do ECHAM para o mês de agosto: a) Termo A, b) Termo B, c) Índice de Haines. Suscetibilidade do ambiente a ocorrências de queimadas no futuro a partir dos dados do ECHAM para o mês de agosto: a) Termo A, b) Termo B, c) Índice de Haines.

Investigando as condições propostas pelo cenário de aquecimento global (Fig. $5 \mathrm{~g}, \mathrm{~h}, \mathrm{i})$, nota-se uma intensificação substancial das condições favoráveis ao desenvolvimento do fogo. Isto é claramente verificado para os estados do Mato Grosso, Pará e Amazonas (Fig. 5i). A Figura (6a,b) mostra a distribuição dos focos de queimadas para o mês de agosto nos anos de 2006 e 2007, de acordo com o satélite NOAA-12. De fato, a região centro-norte do Brasil é a que apresenta o maior 
número de queimadas. Para o ano de 2006, cerca de 25.800 focos de queimadas foram detectados, já em 2007, foram detectados cerca de 21.450 focos de queimadas.

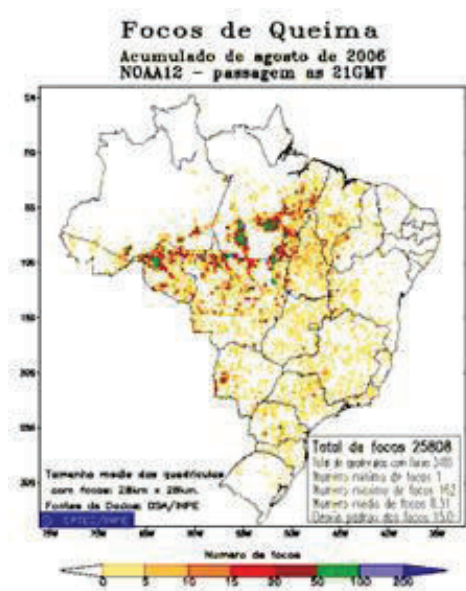

a)

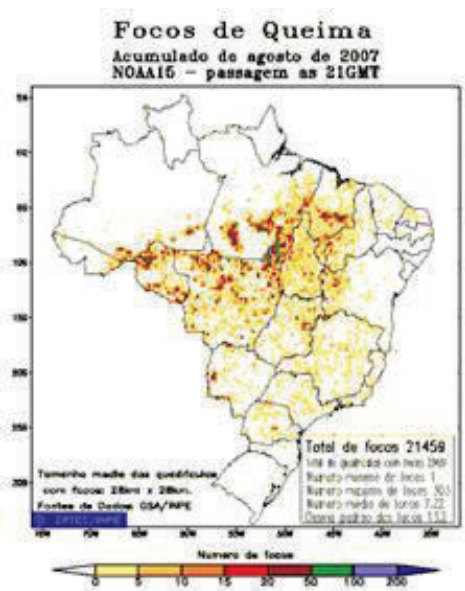

b)

Figura 6 - a) Focos de Queimadas acumuladas do mês de Agosto de 2006

b) Focos de Queimadas acumuladas do mês de Agosto de 2007.

Fonte: Centro de Previsão de Tempo e Estudos Climáticos (CPTEC).

Análise para o mês de setembro

Durante o mês de setembro passa a haver de acordo com os dados do NCEP, uma desintensificação dos termos (A e B), e consequentemente uma diminuição do IH, em comparação ao mês de agosto. Embora ainda possa ser observada a área de risco no Brasil central. A análise dos resultados do ECHAM5 (Fig. 7d,e,f) mostra-se totalmente diferente em termos de espacialização e magnitude quando comparados aos dados do NCEP(Fig. 7a,b,c). Enquanto os resultados do NCEP apresentam a região central do Brasil como mais instável e mais seca, os resultados do ECHAM5 apresentam o Pará e o oeste do nordeste brasileiro (NEB) como mais favorável às queimadas.

Para um cenário futuro de AG, o IH apresenta uma intensificação notória do termo A (Fig. $7 \mathrm{~g}, \mathrm{~h}, \mathrm{i})$. Logo, o poder convectivo é responsável por grande parte do processo que resulta no risco de queimadas, enquanto que o teor de vapor d'água na atmosfera no nível de $850 \mathrm{hPa}$ tem uma menor contribuição. Desta forma, acena-se com a possibilidade de grandes áreas com maior suscetibilidade a queima, a saber: região centro-oeste e região norte. Esta redução do IH em setembro quando comparado a agosto não está de acordo com o aumento no número de focos de calor como mostrado pelas Figuras (8a,b e 6a,b). Áreas em que foram identificadas um alto número de queimadas, como Rondônia e leste do Pará, não mostram condições de risco alto de acordo com o IH. 


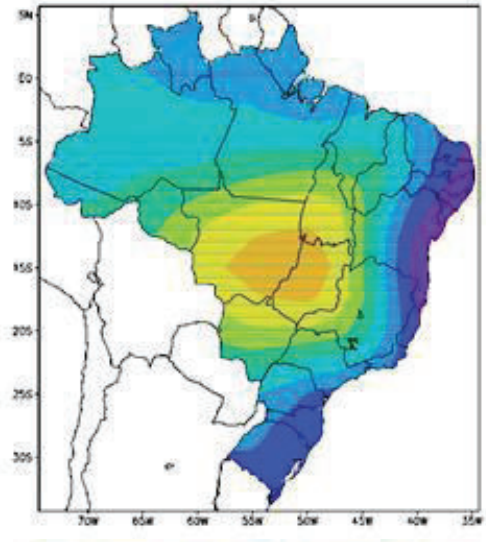

a)
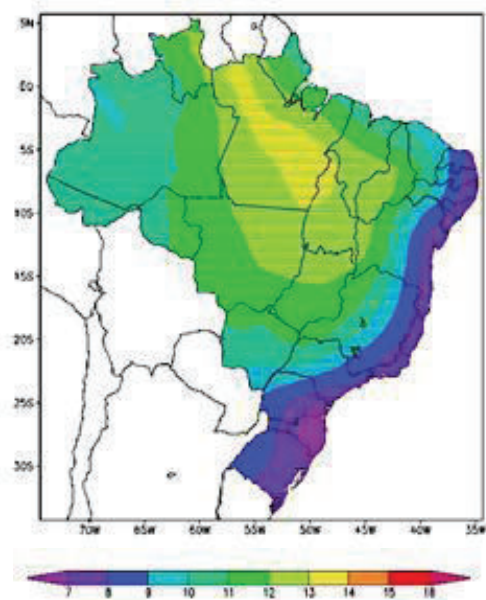

d)

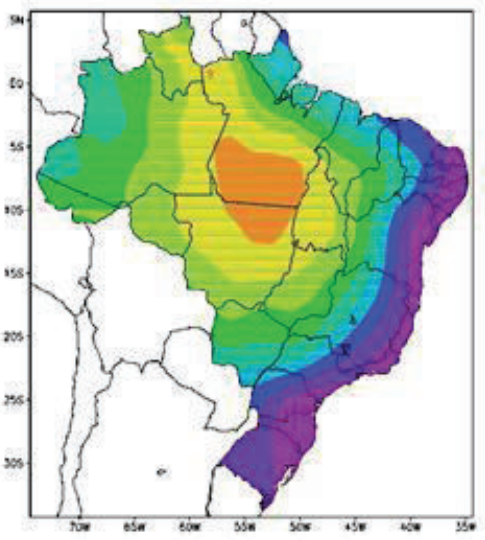

g)
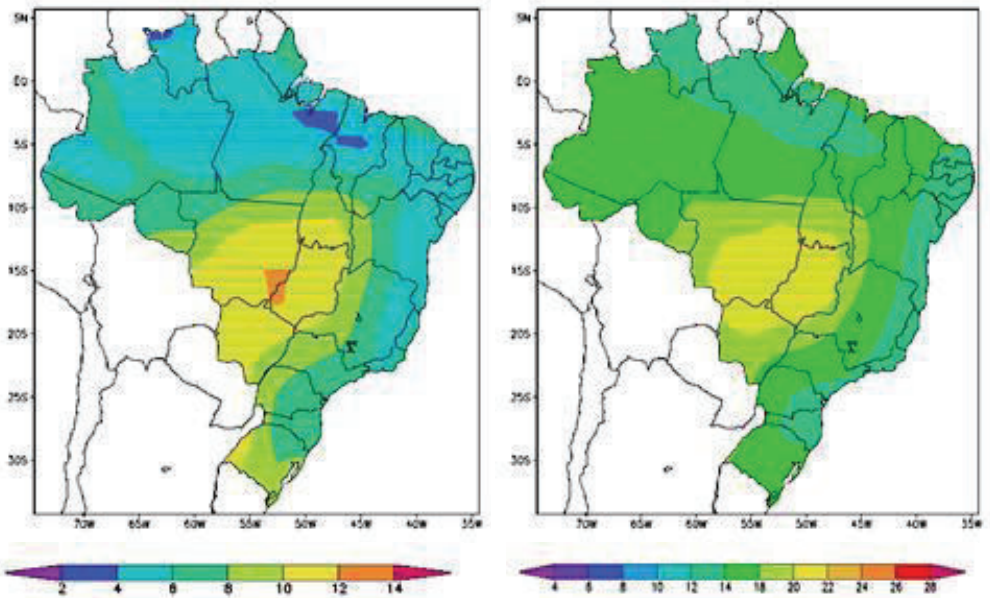

b)
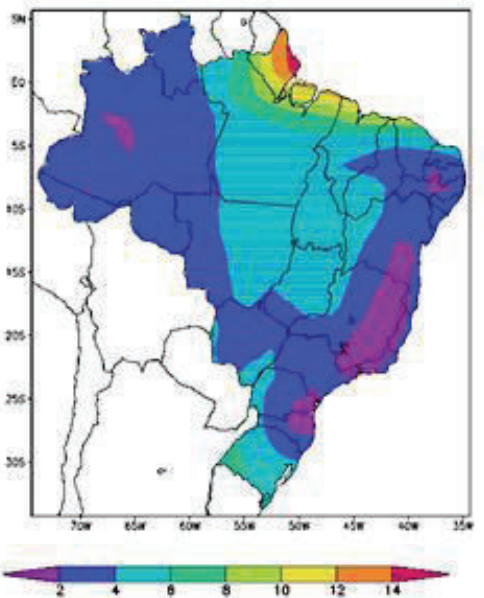

e)

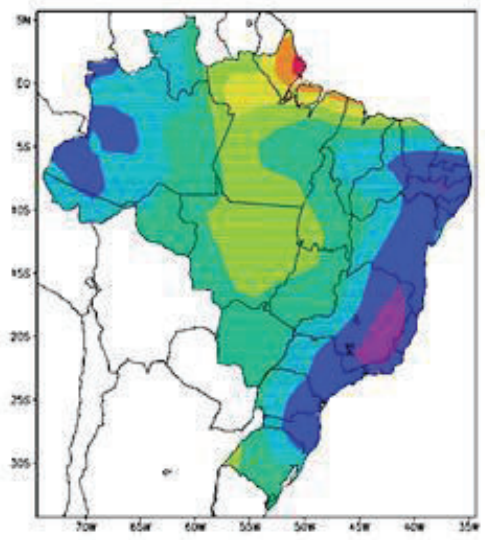

h)

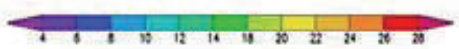

c)
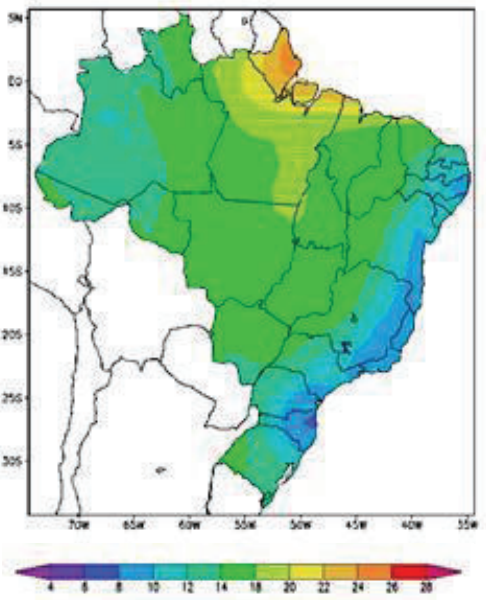

f)

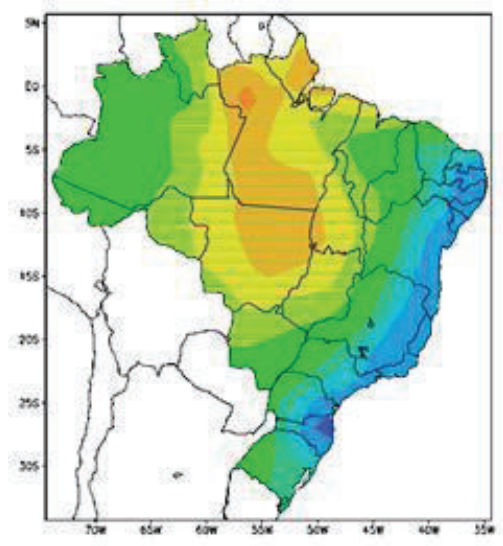

i)

Figura 7 - Suscetibilidade do ambiente a ocorrências de queimadas sob condições atuais a partir dos dados do NCEP para o mês de setembro: a) Termo A, b) Termo B, c) Índice de Haines. Suscetibilidade do ambiente a ocorrências de queimadas sob condições atuais a partir dos dados do ECHAM para o mês de setembro: d) Termo A, e) Termo B, f) Índice de Haines. Suscetibilidade do ambiente a ocorrências de queimadas no futuro a partir dos dados do ECHAM para o mês de setembro: g) Termo A, h) Termo B, i) Índice de Haines.

Setembro é o mês com maior incidência de queimadas principalmente nos estados do Pará, Tocantins e norte do Mato Grosso. Portanto, os resultados com maior confiabilidade são os resultados do ECHAM5, já que se mostraram numa melhor coerência em relação aos focos de queimadas detectados. 


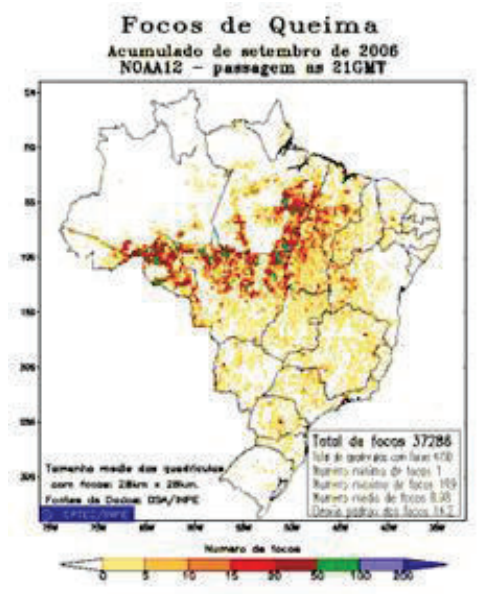

a)

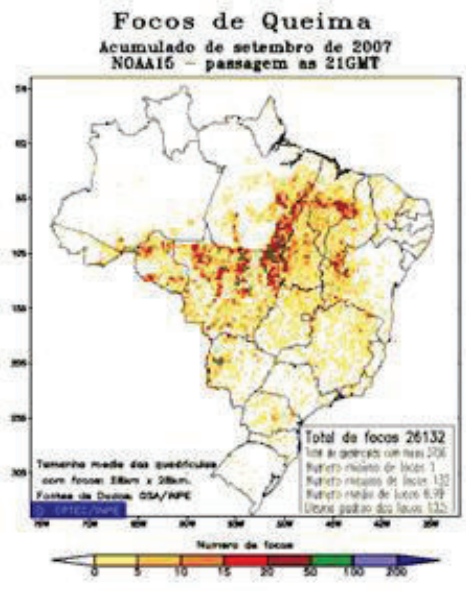

b)

Figura 8 - a) Focos de Queimadas acumuladas do mês de setembro de 2006

b) Focos de Queimadas acumuladas do mês de setembro de 2007

Fonte: Centro de Previsão de Tempo e Estudos Climáticos (CPTEC).

\section{Análise para o Índice de Setzer( IS )}

Análise para o mês de agosto

De acordo com a Figura $(6 a, b)$ que apresentam as distribuições dos focos de queimadas de agosto para os anos de 2006 e 2007, nota-se que o norte do Mato Grosso, Rondônia e sul/leste do Pará, são as áreas com maior predomínio de queimadas. De fato, é sobre estas regiões que se encontram os maiores valores de Tmáx e menores valores de URmín, assim como o período de Secura (PSE) é mais intenso (Fig. 9a,b,c).

A avaliação do IS (Fig. 10a), calculado a partir das condições climáticas atuais, acena para a existência de risco crítico sobre os estados supra-citados. A análise para condições de AG mostra uma intensificação ainda maior da zona crítica ao uso do fogo (Fig. 10b). Ao se incluir a vegetação prevista para as últimas décadas do século XXI, tem-se uma migração da área mais favorável à queima. Sob essas condições, o IS máximo passa a abranger a parte norte do Pará, leste do Amazonas e Rondônia (Fig. 10b). É importante notar que estas áreas, em particular o noroeste do Pará, não apresentam, sob condições atuais, um grande número de queimadas, por ser ainda uma área de mata fechada com pouca presença humana. A Figura (10e) mostra as anomalias entre o risco atual e o risco proposto com base no clima e vegetação futura. Nota-se uma intensificação considerável no risco de fogo, em especial no estado do Amazonas e noroeste do Pará. Isto se deve à conversão da floresta nativa em cerrado, que é a vegetação proposta pelo cenário futuro. Por outro lado, a presença de gramíneas, substituindo o cerrado, diminui o IS no Mato Grosso e sul do Pará. 


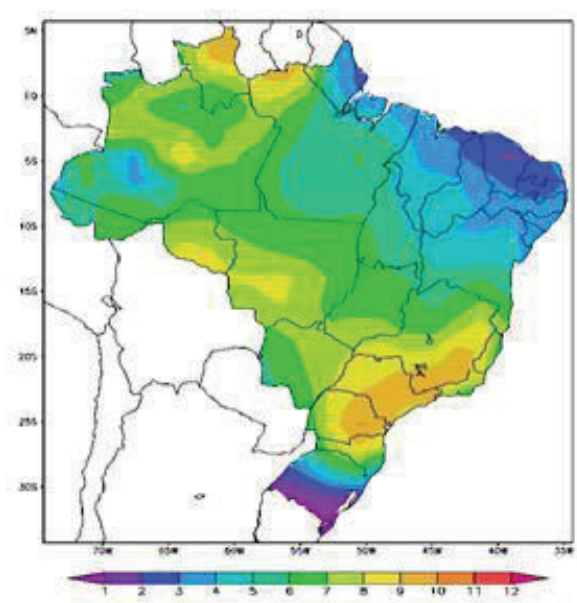

a)

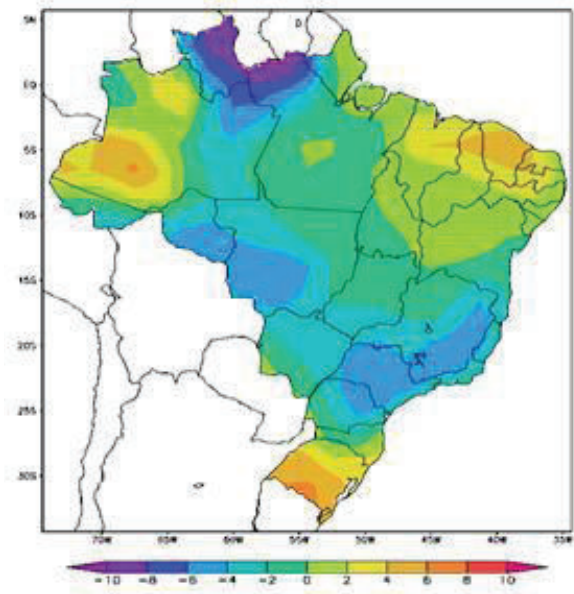

b)

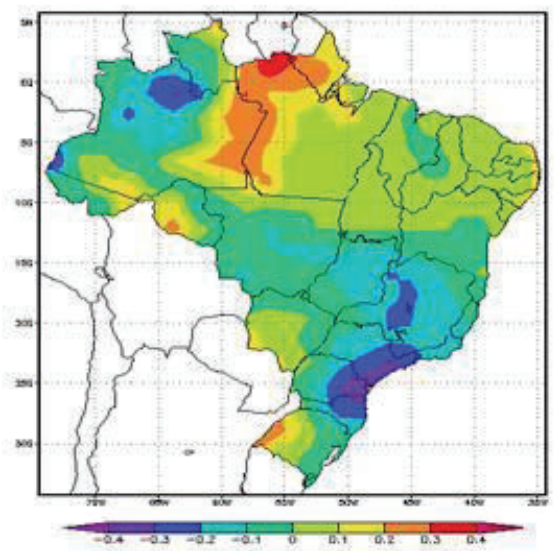

c)

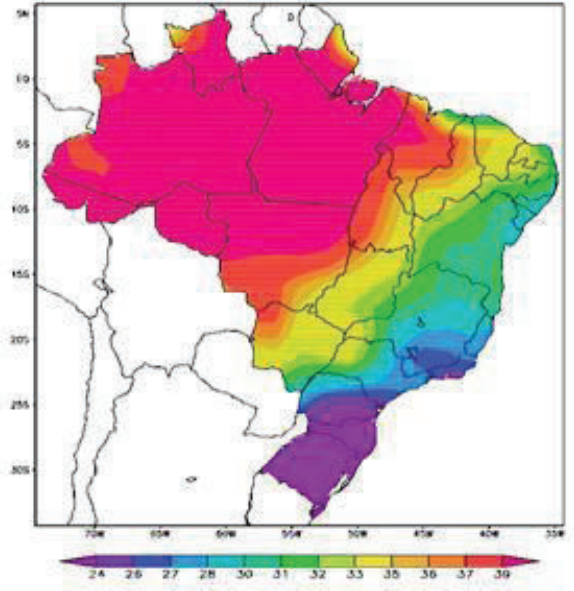

d)

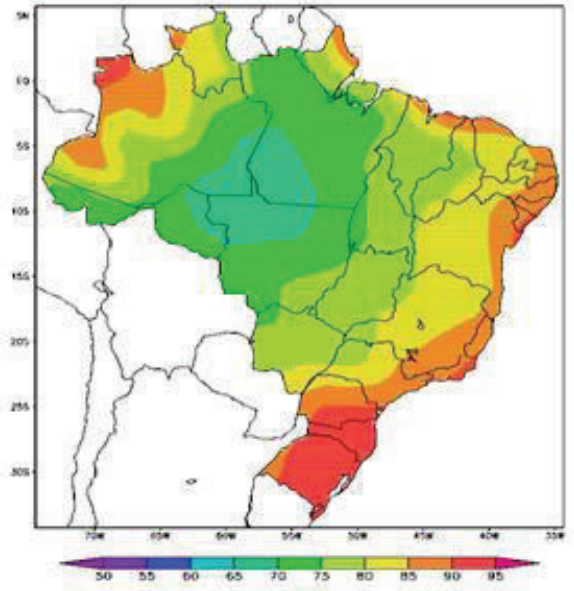

e)

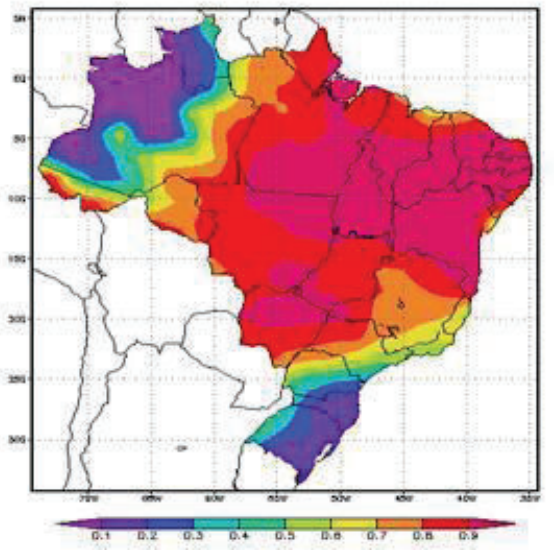

f)

Figura 9 - a) Anomalia da Tmáx entre a simulação de clima futuro e vegetação atual e o presente para agosto; b) o mesmo que (a) para URmín e c) para o PSE, d), e) ,f) mostra a distribuição espacial da Tmáx, URmín e PSE com simulações futuras de clima e vegetação para agosto,respectivamente. 

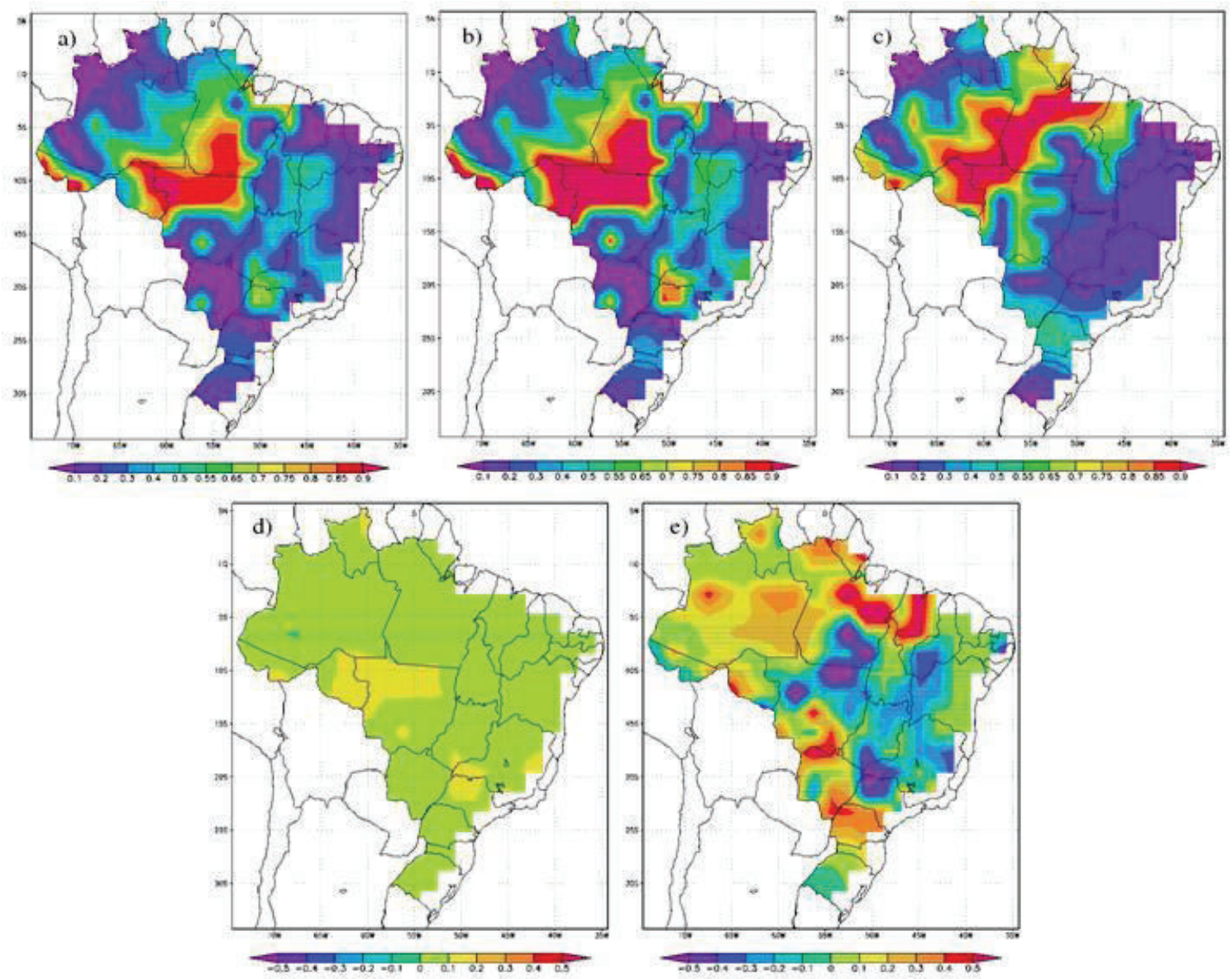

Figura 10 - a) Índice de Setzer (IS) para o clima e vegetação atual em agosto,

b) IS para o clima futuro e vegetação atual em agosto,

c) IS para simulações futuras de clima vegetação em agosto;

d) são as anomalias entre b) e a); e) são as anomalias entre c) e a).

Análise para o mês de Setembro

A evolução das condições climáticas ao longo do ano proporciona considerável mudança nos padrões/distribuições dos campos de Tmáx, URmín e PSE. No mês de setembro, a condição dominante para o estabelecimento do IS é a distribuição de precipitação, ou o PSE (Fig. 11c). É importante salientar que as condições associadas com Tmáx e URmín, em particular no leste do Amazonas são também importantes.

A região centro-sul do Brasil apresenta uma característica ímpar no sentido que as maiores anomalias de Tmáx (Fig. 11a) e mínimas de URmín (Fig. 11b) não são suficientes para produzir uma região de nível crítico do IS. O risco de fogo calculado para as condições atuais (Fig. 12a) confirma as áreas de risco máximo no Mato Grosso e Pará, já mostrando um IS que é caracterizado por um nível moderado. Com o uso dos dados climáticos previsto para o futuro (Fig. 12b), o IS se mantém sobre as mesmas áreas, porém com maiores valores, caracterizando o nível crítico. Para o mês de setembro o emprego da vegetação prevista causa uma redução do IS, exceto no extremo norte do Pará (Fig. 12c). 


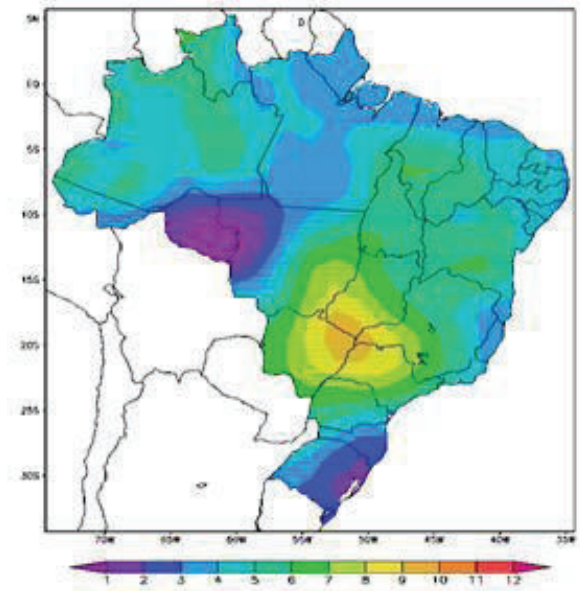

a)

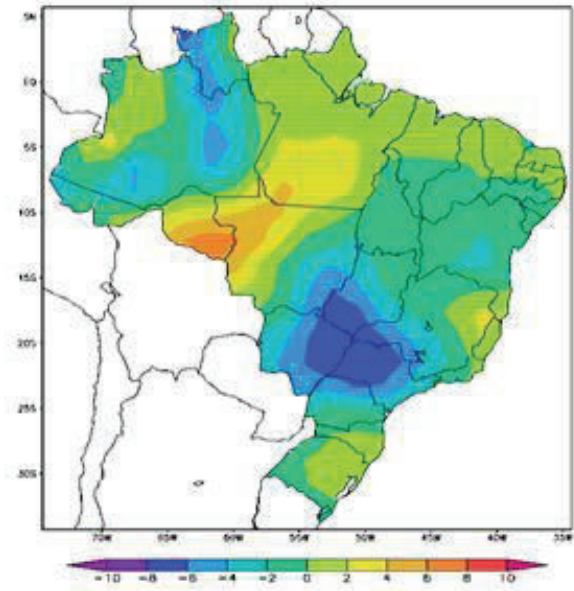

b)

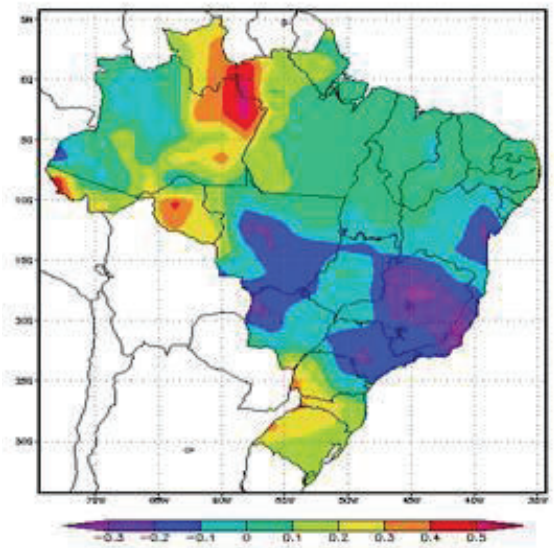

c)

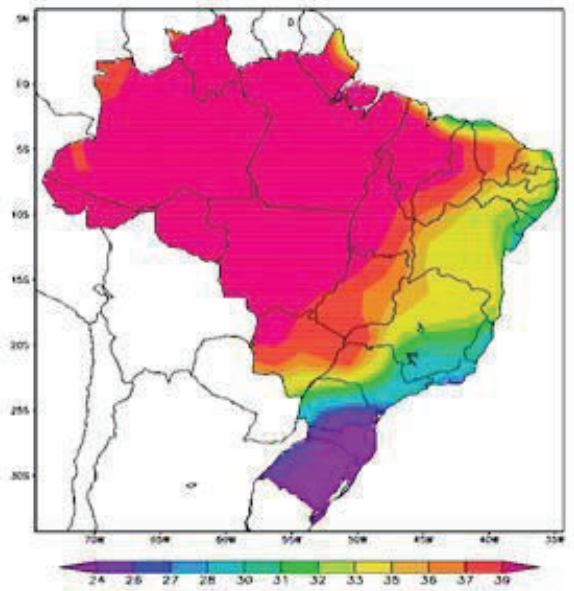

d)

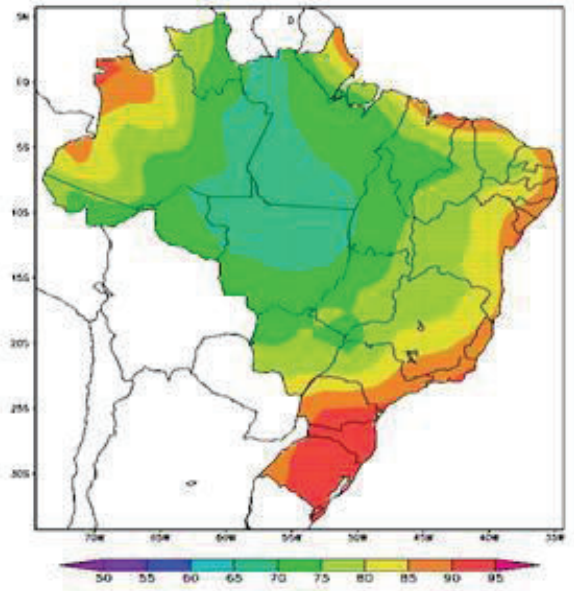

e)

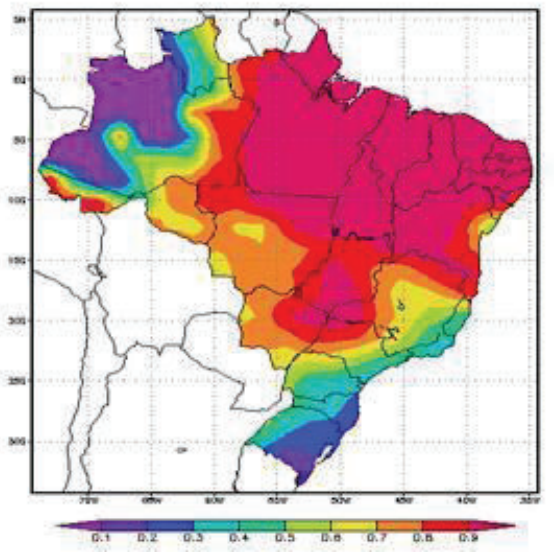

f)

Figura 11 - a) Anomalia da Tmáx entre a simulação de clima futuro e vegetação atual e o presente para setembro; b) o mesmo que (a) para URmín e c) para o PSE, d), e) ,f) mostra a distribuição espacial da Tmáx, URmín e PSE com simulações futuras de clima e vegetação para setembro. 

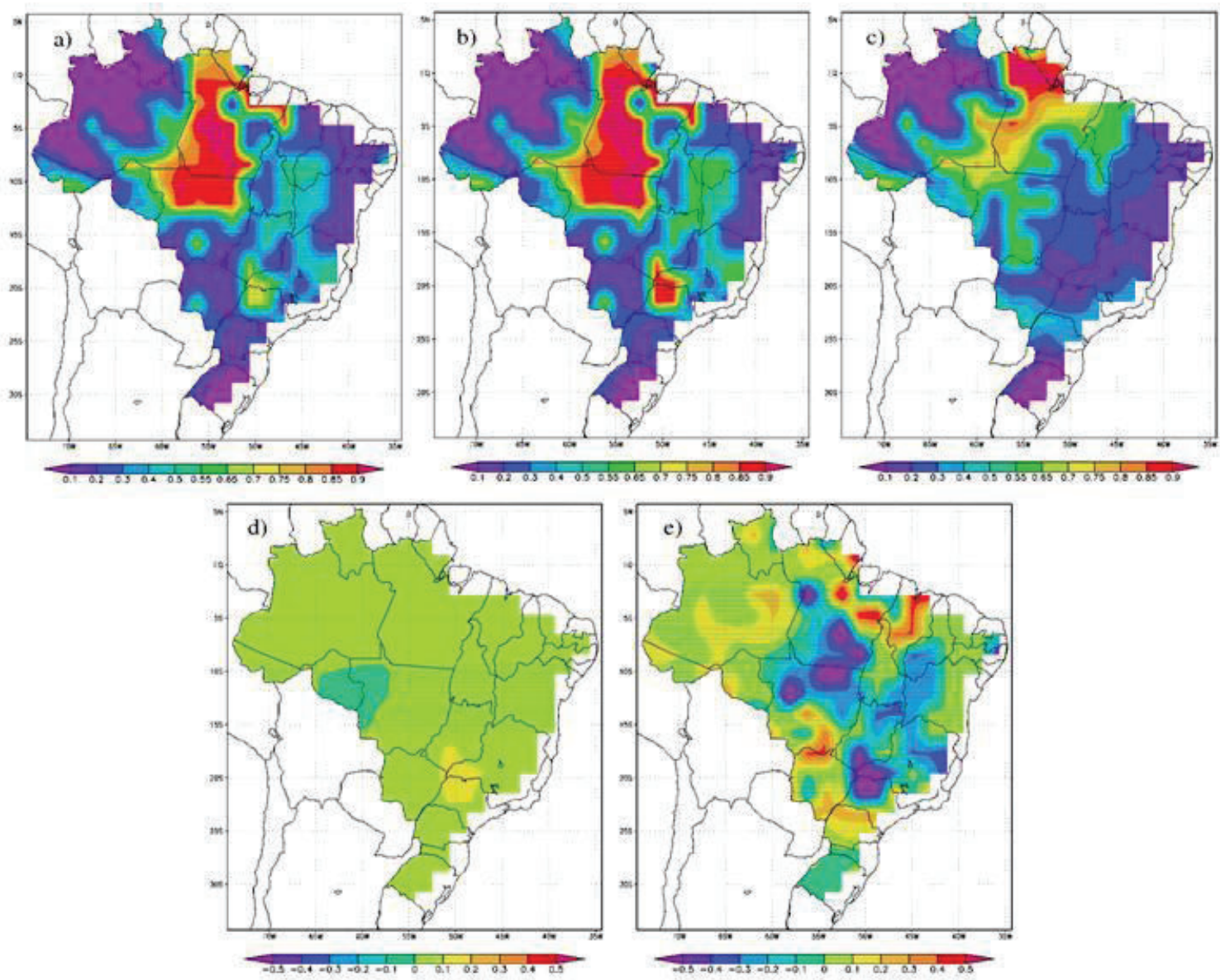

Figura 12 - a) Índice de Setzer (IS) para o clima e vegetação atual para setembro,

b) IS para o clima futuro e vegetação atual para setembro,

c) IS para simulações futuras de clima e vegetação para setembro;

d) são as anomalias entre b) e a); e) são as anomalias entre c) e a).

\section{CONSIDERAÇÕES FINAIS}

Neste trabalho verificou-se os possíveis impactos das variações climáticas no risco de queimadas no Brasil, com o uso do Modelo de Circulação Geral Acoplado Oceano-Atmosfera ECHAM5/ MPI-OM, em condições climáticas atuais e de aquecimento global. Para a validação dos resultados do ECHAM5 utilizou-se os dados de reanálises do NCEP. As análises climáticas, para os dados do ECHAM5 e NCEP, mostraram que o modelo representa relativamente bem o período atual em termos de temperatura, precipitação e umidade relativa, já que o mesmo consegue capturar os padrões climatológicos dominantes, em particular sobre a região Amazônica. Sobre a região central do Brasil, o modelo tende a superestimar a temperatura e a precipitação, e subestimar a umidade relativa.

Com base nas análises do risco de queimadas propostos pelo IH a partir de duas condições climáticas distintas, foi encontrado que sob condições atuais as principais áreas de risco de queimadas concentram-se na região centro-oeste e norte do Brasil, principalmente no centro-norte do Mato Grosso, com máxima atividade no mês de agosto. Para o final do século, em um cenário de aquecimento global, o IH apresenta áreas mais abrangentes como também maiores valores no risco de queimadas.

O cálculo do IS, a partir de dois tipos de vegetação, um de acordo com as condições atuais e outro como proposto para o futuro em um cenário de aquecimento global, mostra que o IS futuro é extremamente sensível a condição imposta pela vegetação, no sentido que as áreas que tiveram a substituição da floresta por cerrado, apresentaram um maior risco de queimadas. Por outro lado, 
áreas onde o cerrado foi substituído por gramíneas tiveram IS reduzido. Isto mostra que, de acordo com as condições atmosféricas anômalas previstas para o futuro, pode-se esperar condições extremamente favoráveis ao desenvolvimento de queimadas de grande porte, principalmente na região Amazônica. Com base nos resultados apresentados, pode-se ainda sugerir que a substituição da floresta amazônica por cerrado, propiciará um aumento na suscetibilidade atmosférica a queimadas.

A comparação entre o IH e o IS mostra que o IH apresenta um menor índice de risco de queimadas, em comparação ao IS. Os índices também diferem em termos de regiões mais propensas às queimadas de grande porte.

Sabe-se que a maior parte das previsões das condições climáticas e atmosféricas devido às mudanças globais, são produzidas pela extrapolação de estudos locais e de curta duração para cenários globais e de longo prazo. Estes são, todavia, fontes de incertezas e imprecisões. As interações dos elementos climáticos ocorrem de forma complexa e estão associadas às projeções dos diferentes modelos de circulação geral da atmosfera, que por sua vez diferem substancialmente nos seus resultados. A depender do cenário econômico usado (por exemplo: A2, A1B, B2, B1), as previsões de temperatura, precipitação e umidade variam tanto em magnitude como em suas distribuições espaciais. Logo os resultados aqui apresentados são inteiramente dependentes dos campos atmosféricos anteriormente citados, e que estão também associados a incertezas.

\section{REFERÊNCIA BIBLIOGRÁFICA}

AGEE, J.K. Fire and pine ecosystems, in Ecology and biogeography of Pinus (ed. D.M. Richardson). Cambridge University Press, Cambridge, p.193-218, 1998.

COOK, K., VIZY, E.K. Effects of Twenty-First-Century climate change on the Amazon rain forest. Journal of Climate, v. 21, n 3, p. 542-560, 2008.

COSTA, M.H., YANAGI, SILVIA N.M, SOUZA, P.J.O.P., RIBEIRO, A., ROCHA, E.J.P. Climate change in Amazonia caused by soybean cropland expansion, as compared to caused by pastureland expansion. Geophysical Research Letters, v. 34, p. L07706, 2007.

CRUZ, F.W., BURNS, S.J., KARMANN, I., SHARP, W.D., VUILLE, M., CARDOSO, A.O., FERRARI, J.A., DIAS, P.L.S., Jr, O.V. Insolation-driven changes in atmospheric circulation over the past 116,000 years in subtropical Brazil. Nature, v. 434, p. 63-66, 2005. doi: 10.1038/nature03365

EMERY, W., THOMSON, R. Data analysis methods in physical oceanography. Pergamon Press, Elsevier Science, Oxford, p. 643, 1997

FERRAZ-VICENTINI, K.R. História do fogo no cerrado: uma análise palinológica. Tese de Doutorado, Universidade de Brasília, (DF), 1999.

HAINES, D.A. A lower atmospheric severity index for wildland fires. Natl. Wea. Dig., v. 13, pp. 23-27, 1988.

HINES, K.M., BROMWICH, D.H., MARSHALL, G.J. Artificial surface pressure trends in the NCEP-NCAR reanalysis over the Southern Ocean and Antarctica. Journal of Climate v. 13, p. 3940-3952, 2000.

JUNGCLAUS, J.H, KEENLYSIDE, N., BOTZET, M., HAAK, H., LUO, J.-J., LATIF, M., MAROTZKE, J., MIKOLAJEWICZ, U., ROECKNER, E. Ocean circulation and tropical variability in the coupled model ECHAM5/MPI-OM, Journal of Climate, v. 19, p. 3952-3972, 2006.

JUSTINO, F.B., TIMMERMANN, A., KREBS, U., SOUZA, E. Synoptic reorganization of atmospheric flow during the Last Glacial Maximum. Journal of Climate, v. 18, pp. 2826-2846, 2004.

KIRCHOFF, V. SCAR-B proceedings, Transec Editorial, INPE, São José dos Campos,(SP), p. 208, 1997. LATURNER, N., SCHERER, H.W. As queimadas e os incêndios florestais em Mato Grosso. Revista Geonotas, v. 8, 2004.

MARSLAND, S.J., HAAK, H., JUNGCLAUS, J.H., LATIF, M., RÖSKE, F. The Max Planck Institute global ocean/sea-ice model with orthogonal curvilinear coordinates. Ocean Modell, v. 5, p. 91-127, 2003. RIBEIRO, G.A.; SOARES, R.V. Caracterização do material combustível florestal e efeitos da queima controlada sobre sua redução em um povoamento de Eucalyptus viminalis. Cerne, Lavras, v. 4, n 1, p. 57-72, 1998. 
SALGADO-LABOURIAU, M.L., FERRAZ-VICENTINI, K.R. Fire in the cerrado 32,000 years ago. Current Research in the Pleistocene, v. 11, p. 85-87, 1994.

SETZER, A., PEREIRA, M.C., PEREIRA Jr, A.C. O uso de satélites NOAA na detecção de queimadas no Brasil. Climanálise, v. 7, n 8, pp. 40-53, 2002.

SETZER, A., SISMANOGLU, R.A. Queimadas no Brasil. Climanálise Boletim de Monitoramento e Análise Climática, CPTEC/INPE, v. 21, n. 01, p. 1, 2006

SISMANOGLU, R.A., SETZER, A., JUSTINO, F., LIMA, W.F.A. Avaliação inicial do desempenho do risco de fogo gerado no CPTEC. Anais do XII Congresso Brasileiro de Meteorologia, 2002.

WILKS, D.S. Statistical methods in the atmospheric sciences: an introduction. San Diego, California, Academic Press, p. 467, 1995.

WINKLER, J.A., POTTER, B., WILHELM, D., SHADBOLT, R., BIAN, X., PIROMSOPA, K. A cimatology of the Haines Index for North America derived from NCEP/NCAR reanalysis fields. Sixth Fire and Forest Meteorology Symposium, American Meteorological Society. (2005).

Trabalho enviado em dezembro de 2011

Trabalho aceito em janeiro de 2012 